\title{
Lentiviral-mediated RNAi targeting caspase-3 inhibits apoptosis induced by serum deprivation in rat endplate chondrocytes in vitro
}

\author{
L. Ding ${ }^{1}$, J.P. $W u^{1}$, G. Xü ${ }^{2}$, B. Zhu ${ }^{1}$, Q.M. Zeng ${ }^{1}$, D.F. $\mathrm{Li}^{1}$ and W. $\mathrm{Lu}^{1}$ \\ ${ }^{1}$ Department of Orthopaedics, Jinshan Hospital, Fudan University, Shanghai, China \\ ${ }^{2}$ Center Laboratory, Jinshan Hospital, Fudan University, Shanghai, China
}

\begin{abstract}
Current studies find that degenerated cartilage endplates (CEP) of vertebrae, with fewer diffusion areas, decrease nutrient supply and accelerate intervertebral disc degeneration. Many more apoptotic cells have been identified in degenerated than in normal endplates, and may be responsible for the degenerated grade. Previous findings suggest that inhibition of apoptosis is one possible approach to improve disc regeneration. It is postulated that inhibition of CEP cell apoptosis may be responsible for the regeneration of endplates. Caspase-3, involved in the execution phase of apoptosis, is a candidate for regulating the apoptotic process. In the present study, CEP cells were incubated in $1 \%$ fetal bovine serum. Activated caspases were detected to identify the apoptotic pathway, and apoptosis was quantified by flow cytometry. Lentiviral caspase-3 short hairpin RNA (shRNA) was employed to study its protective effects against serum deprivation. Silencing of caspase- 3 expression was quantified by reverse transcription-polymerase chain reaction and Western blots, and inhibition of apoptosis was quantified by flow cytometry. Serum deprivation increased apoptosis of rat CEP cells through activation of a caspase cascade. Lentiviral caspase-3 shRNA was successfully transduced into CEP cells, and specifically silenced endogenous caspase-3 expression. Surviving cells were protected by the downregulation of caspase-3 expression and activation. Thus, lentiviral caspase-3 shRNA-mediated RNAi successfully silenced endogenous caspase-3 expression, preventing inappropriate or premature apoptosis.
\end{abstract}

Key words: Cartilaginous endplate; Chondrocytes; RNA interference; Apoptosis; Caspase-3; Serum deprivation

\section{Introduction}

Degeneration of the intervertebral disc (IVD) plays a critical role in the pathogenesis of spinal disorders, and is also the main cause of back or cervical pain and morbidity $(1,2)$. Treatment or prevention of degenerative disc disease is not easily achieved because its molecular processes are poorly understood. The cartilage endplate (CEP) is the main source of nutrients for the IVD (3-6). Degeneration of the CEP dramatically decreases disc biomechanical integrity and nutrition, resulting in breakdown of the metabolic equilibrium of the extracellular matrix, and ultimately accelerating disc degeneration (1,3,4,7-11). Apoptotic cells have been identified in degenerated endplates, and their quantity has a positive relationship with the degeneration grade of disk diseases (7). Ariga et al. (7) reported that apoptosis was particularly noticeable in CEP of advanced age, which was more evident in a surgically treated group than in a naturally aged group. Prevention of premature apoptosis of endplate chondrocytes is a potential therapeutic strategy in maintaining IVD health and preventing spondylopathy

Two major pathways of cellular apoptosis have been identified, the death-inducing signaling complex pathway and the mitochondrial pathway (12). Which of these apoptosis pathways is induced depends upon the activation of the caspase cascade, including initiators (caspases 8 and 9) and executioners (caspases 3 and 6) (13). Caspase-3, characterized as both a marker and an ultimate executioner, is a candidate for inhibiting the apoptosis process $(14,15)$. Sudo and Minami (15) demonstrated that downregulation of endogenous caspase- 3 expression can successfully prevent apoptosis of the nucleus pulposus both in vitro and in vivo; the effects on CEP cells have yet to be investigated. 
RNA interference (RNAi) is a posttranscriptional gene silencing mechanism (16) that has emerged as a powerful method for silencing gene expression, and is widely used for gene therapy $(17,18)$. However, two major disadvantages of small interfering RNA (siRNA) are low delivery efficiency and transient gene silencing. Virus vectors encoding short hairpin RNAs (shRNAs) have been exploited to overcome these obstacles (19). Lentivirus vectors, which have favorable longevity, high delivery rates, and minimal immunogenicity, have been used in large-scale RNAi assays to study gene functions $(20,21)$. RNAi has been used to explore the effects of inhibiting gene expression in nucleus pulposus cells $(15,22,23)$.

In the present study, a lentivirus vector encoding shRNA was used to target caspase- 3 and to investigate its anti-apoptosis effects in CEP cells.

\section{Material and Methods}

\section{Cell isolation and culture}

Sprague-Dawley rats, approximately 12 weeks of age and $400 \mathrm{~g}$ in weight, were used in the current study. The rats were killed by cervical dislocation and the lumbar spines were obtained within $1 \mathrm{~h}$ of death. The discs were carefully dissected under a microscope to obtain only the CEPs, which were minced into small pieces $\left(<0.3 \mathrm{~mm}^{3}\right)$ under aseptic conditions. To isolate the chondrocytes, the tissues were sequentially treated with $0.25 \%$ trypsin (Sigma, USA) at $37^{\circ} \mathrm{C}$ for $120 \mathrm{~min}$ followed by $0.02 \%$ collagenase (Sigma) at $37^{\circ} \mathrm{C}$ for $24 \mathrm{~h}$. After enzymatic digestion, the tissues were filtered through a $100-\mathrm{mm}$ cell strainer (BD Biosciences, USA), and then washed with phosphate-buffered saline (PBS). Afterward, the cells were released from the matrix by centrifugation at $1000 \mathrm{~g}$ for $5 \mathrm{~min}$, placed on 6 -well plates at $2 \times 10^{4}$ cells/well, and maintained in Dulbecco's modified Eagle's medium (DMEM; Gibco, USA) supplemented with $10 \%$ fetal bovine serum (FBS; Gibco), $100 \mathrm{U} / \mathrm{mL}$ penicillin, and $100 \mu \mathrm{g} / \mathrm{mL}$ streptomycin under $5 \% \mathrm{CO}_{2}$ in a humidified incubator at $37^{\circ} \mathrm{C}$. Primary chondrocytes were maintained in highdensity monolayer culture for 1 week. Then, the cells were trypsinized and subcultured on 6-well plates, which were used in the following experiments as secondary cells.

\section{Construction of lentivirus vectors}

A DNA template and oligonucleotides corresponding to the caspase-3 gene (Gene ID NM_012922), which had proved to be the most efficient for use in RNAi in previous experiments, were targeted. The oligonucleotide sequences were designed and synthesized as follows: caspase-3-siRNA-F: 5'-TGCTGATATCATCGTCAGTTC CACTGGTTTTGGCCACTGACTGACCAGTGGAAGACG ATGATAT-3', caspase-3-siRNA-R: 5'-CCTGATATCATC GTCTTCCACTGGTCAGTCAGTGGCCAAAACCAGTGG AACTGACGATGATATC-3'.

The combined sequences of the enhanced green fluorescent protein (EGFP) gene and the caspase-3 siRNA were cloned into the Ascl and Pmel sites of the pLenti6.3MCS vector (R\&S Biotechnology, China) containing a CMV-driven GFP reporter. An siRNA unrelated to human gene sequences was used as a negative control. All constructed plasmids were confirmed by sequence analysis. All plasmids were transfected into 293T cells using a packaging vector mix (Invitrogen, USA). Supernatants containing lentiviruses were harvested at $96 \mathrm{~h}$ after transduction. We performed subsequent purification by ultracentrifugation at $4000 \mathrm{~g}, 4^{\circ} \mathrm{C}$ for $10 \mathrm{~min}$, and stored the isolated lentiviruses at $-80^{\circ} \mathrm{C}$ until use. The titer of the lentiviruses was $1.5 \times 10^{6}$.

\section{Transfection of lentivirus}

The secondary cells were transferred to 6-well plates at a density of $5 \times 10^{5}$ cells/well in DMEM with $10 \%$ FBS without antibiotics the day before transduction procedures. When they had reached $80 \%$ confluence, the cells were transfected with the recombinant experimental virus or the control virus at a multiplicity of infection of 50 with polybrene $(5 \mu \mathrm{g} / \mathrm{mL})$ for $24 \mathrm{~h}$. All cells were placed in fresh DMEM containing 10\% FBS without antibiotics and cultured in this complete medium for $48 \mathrm{~h}$. The transduction efficiency was determined by fluorescence microscopy.

\section{Cell treatments}

We used 1\% FBS to investigate the apoptotic effects of serum deprivation on CEP cells. Apoptosis was assessed at $48 \mathrm{~h}$. The cells were infected with either the caspase-3 shRNA vector (CEP-caspase-3) or the negative control vector (CEP-NC) in complete medium. An additional, untransfected group (CEP-CTR) was included in the analysis. The three groups were incubated in medium containing $1 \%$ FBS for the $48 \mathrm{~h}$ before the apoptosis assay.

\section{Measurement of caspase activation}

Caspase-3, -8, and -9 enzymatic activities were assessed using a caspase activity kit (Beyotime, China) according to the manufacturer's protocol. In brief, cells were replated at $1 \times 10^{5}$ cells/well on a 12 -well plate. Cell lysates were prepared, and $2 \mathrm{mM}$ caspase-3, -8 , and -9 substrates (Ac-DEVD-pNA, Ac-IETD-pNA, Ac-LEHD-pNA, respectively) were added to the lysates. The mixtures were incubated on ice for $1 \mathrm{~h}$, and the absorbance at $405 \mathrm{~nm}$ was measured with an ELISA reader (Beckman Coulter, Inc., USA). Caspase activities were calculated as the change in absorbance at $405 \mathrm{~nm}$.

\section{Detection of apoptosis}

Apoptosis of cells incubated in 1\% FBS was determined by staining with fluorescein isothiocyanate (FITC)labeled annexin $\mathrm{V}$ and propidium iodide (PI; PharMingen, USA), according to the manufacturer's instructions. The 
cells were stained simultaneously with FITC-labeled annexin $\mathrm{V}$ and $\mathrm{PI}$ and scored as follows: 1) annexin $\mathrm{V}-$ $\mathrm{PI}-$ (viable cells); 2 ) annexin $\mathrm{V}+/ \mathrm{PI}-$ (cells in the initial stages of apoptosis); 3 ) annexin $\mathrm{V}+/ \mathrm{PI}+$ (cells in the advanced stages of apoptosis), and 4) annexin V-/PI+ (necrotic cells). To quantify apoptosis, the cells were washed with cold PBS and then suspended in binding buffer. The cells were stained with $5 \mu \mathrm{L}$ annexin V-FITC and $10 \mu \mathrm{L} \mathrm{PI}$ and then analyzed using FACScan flow cytometry (FCM; Becton Dickinson, USA) at 48 h. 4',6Diamidino-2-phenylindole (DAPI, Beyotime) was added to the culture medium to determine morphological changes during apoptosis; and the fragmentation of the nucleus and chromatin condensation were examined by fluorescence microscopy.

The three groups (CEP-caspase-3, CEP-NC, and CEP-CTR) at a density of $1 \times 10^{5}$ cells/well were incubated in 1\% FBS for 24 and $48 \mathrm{~h}$, and harvested after trypsinization. Apoptosis of cells transfected with EGFP and control group cells was determined by staining with annexin $\mathrm{V}$ phycoerythrin (PE) (Beyotime), and analyzed using FCM.

\section{Reverse transcription-polymerase chain reaction (RT-PCR)}

RT-PCR was performed to detect caspase- 3 mRNA, and $\beta$-actin was used as the internal standard control. Briefly, total RNA was extracted with Trizol reagent (Invitrogen) following the manufacturer's instructions. Single-strand cDNA templates were prepared from $1 \mu \mathrm{g}$ total RNA using the RT-for-PCR kit (Invitrogen). Specific cDNAs were then amplified by PCR using the following primers: caspase-3 forward: 5'-GAAATTCAAGGGACG GGTCA-3', caspase-3 reverse: 5'-TTCTTTGCATGGAAA GTGGC-3', $\beta$-actin forward: 5'-GCTATGTTGCCCTAGA CTTCGA-3', and $\beta$-actin reverse: 5'-GATGCCACAGGA TTCCATACC-3'

PCR amplification from cDNA was performed in a final volume of $20 \mu \mathrm{L}$, cycling conditions were denaturation at $95^{\circ} \mathrm{C}$ for $15 \mathrm{~s}$, annealing at $59^{\circ} \mathrm{C}$ for $20 \mathrm{~s}$, and elongation at $72^{\circ} \mathrm{C}$ for $20 \mathrm{~s}$, and the optimal cycle number was 40 cycles. PCR products were subjected to amplification curve analysis, and quantified using SYBR Green (Invitrogen). Caspase-3 expression data were normalized to $\beta$-actin, and were shown as ${ }^{\Delta \Delta} \mathrm{Ct}$. Caspase- 3 mRNA was quantified after incubation in $1 \%$ FBS for $48 \mathrm{~h}$.

\section{Western blot analysis}

The protein expression of procaspase- 3 and active caspase-3 was detected by Western blot analysis according to the kit manufacturer's instructions. Total protein was extracted with protein-loading buffer. Total protein concentration was determined by the bicinchoninic acid (BCA) assay (Sigma). Protein extracts were separated by $8-12 \%$ sodium dodecyl sulfate-polyacrylamide gel electrophoresis and transferred to nitrocellulose membranes. The membranes were blocked with $5 \%$ nonfat dry milk in Tris-buffered saline with Tween 20 (TBST) for $1 \mathrm{~h}$ at $37^{\circ} \mathrm{C}$, and incubated overnight at $4^{\circ} \mathrm{C}$ in TBST with the anti-procaspase- 3 or anti-active-caspase- 3 antibody (dilution 1:200) and anti- $\beta$-actin antibody (dilution $1: 2000)$. Following incubation with horseradish peroxidase-conjugated anti-rabbit secondary antibody (dilution 1:5000) for $1 \mathrm{~h}$, the membranes were treated with ECL Plus (Beyotime Institute of Biotechnology, China) according to the manufacturer's instructions. $\beta$-actin was used as a control to verify equal protein loading. All antibodies were supplied by the Beyotime Institute of Biotechnology.

\section{Statistical analysis}

All measurements were carried out using the same instrument under the same experimental conditions and independently performed at least three times to ensure consistency. Data are reported as means $\pm S D$, and significant differences were analyzed by one-way ANOVA among groups and by the Student $t$-test. $\mathrm{P}<0.05$ was considered to be significant.

\section{Results}

\section{Serum deprivation induces apoptosis of rat CEP cells mediated by caspase- 3}

Figure $1 \mathrm{~A}$ shows that CEP cells underwent apoptosis after incubation in $1 \%$ FBS for $48 \mathrm{~h}$, as determined by $\mathrm{DAPI}$ staining. Figure $1 \mathrm{~B}$ shows that CEP cells displayed apoptotic cell death, as determined by double staining with annexin V-FITC and PI. The mean percentage of apoptotic cells, including early (annexin V+/PI-) and late (annexin $\mathrm{V}+/ \mathrm{PI}+$ ) apoptosis, was notably increased in $1 \%$ FBS compared with $10 \%$ FBS $(22.3 \pm 0.58$ vs $10.06 \pm 0.35 \%, P<0.05$; Figure $1 \mathrm{~B})$. We found that there were more early stage apoptotic cells in the $1 \%$ FBS group than in the $10 \%$ FBS group (12.2 \pm 0.37 vs $7.88 \pm 0.33 \%, P<0.05)$, and more late stage apoptotic cells were also observed in the $1 \%$ FBS group than in the $10 \%$ FBS group $(10.1 \pm 0.20$ vs $2.18 \pm 0.22 \%, P<0.05)$.

To quantify the enzymatic activation of the caspase cascade during apoptosis, we determined the changes in caspase-3, -8, and -9 activities. As shown in Figure 1C, caspase-3, -8, and -9 activities were increased by 4-, 3-, and 4 -fold, respectively, after incubation in $1 \%$ FBS for $48 \mathrm{~h}$. These results strongly suggest that serum deprivation induced CEP cellular apoptosis by caspase activation.

\section{Downregulation of endogenous caspase-3 mRNA and protein expression in CEP cells by lentiviral-mediated RNAi}

The lentiviral shRNA was successfully constructed and confirmed by sequence analysis, and the transduction rate of the lentivirus was approximately $90 \%$ at $72 \mathrm{~h}$ (Figure 2). Procaspase-3 and active caspase-3 proteins were assessed by Western blot analysis after incubation 


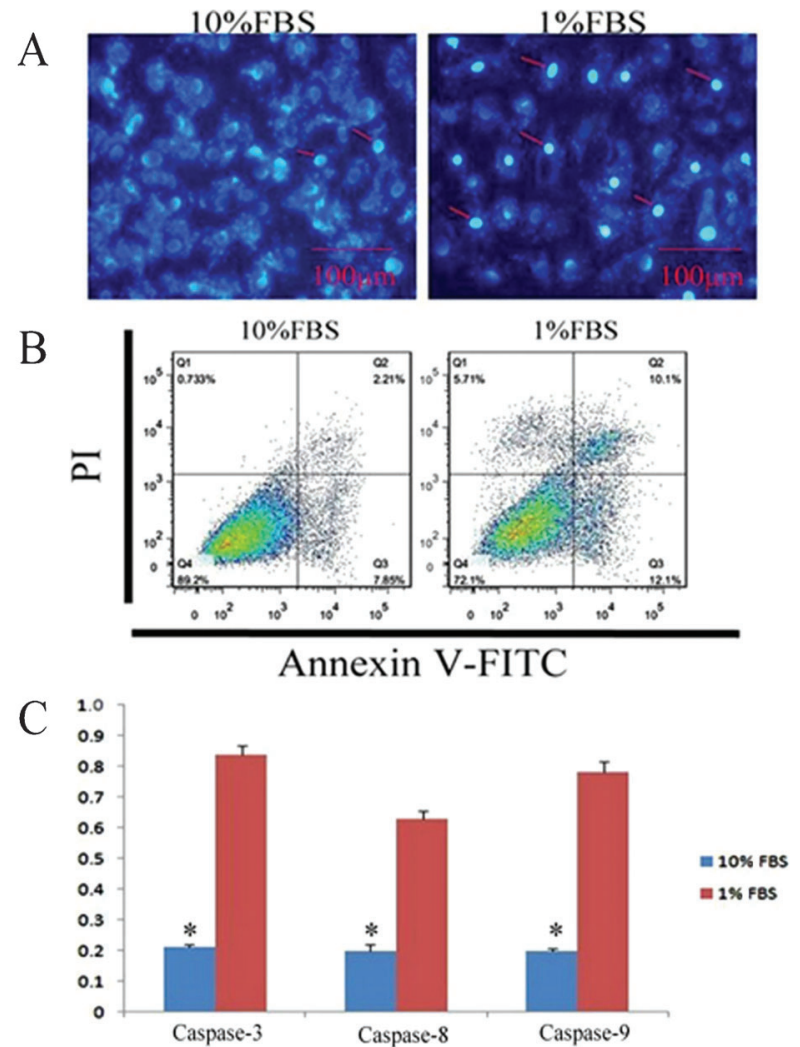

Figure 1. Effects of serum deprivation on cartilage endplate cells after treatment for $48 \mathrm{~h}$. A, DAPI staining of apoptotic bodies assessed by fluorescence microscopy $(400 \times)$. B, Representative graphs obtained by flow cytometry. C, Assay of caspase- $3,-8$, and -9 activities. ${ }^{*} \mathrm{P}<0.05$ vs $1 \%$ fetal bovine serum (FBS) (Student $t$ test). PI: propidium iodide; FITC: fluorescein isothiocyanate.

in $1 \%$ FBS for $48 \mathrm{~h}$. As shown in Figure 3B, the levels of procaspase- 3 and active caspase- 3 in the CEP-NC group increased almost 4- and 2-fold, respectively, over the experimental group, according to gray scale analysis. As expected, the caspase-3 mRNA level decreased in parallel with the protein expression in the CEP-caspase3 group, and was only $44 \%$ of that in the CEP-NC group (Figure $3 A$ ). These results show that caspase- 3 gene expression was successfully knocked down by the lentivirus-mediated RNAi.

\section{RNAi reduces apoptosis of vertebral CEP cells}

To determine whether silencing caspase- 3 had an inhibitory effect on apoptosis of CEP cells, we qualitatively and quantitatively assessed the apoptosis rate of cells stained with PE-labeled annexin $\mathrm{V}$ after incubation in $1 \%$ FBS for 24 and $48 \mathrm{~h}$. FCM analysis showed that the apoptosis rate of the CEP cells (annexin $\mathrm{V}-/ \mathrm{PE}+$ ) was significantly lower after lentivirus transduction (Figure 4A and $\mathrm{B}$ ). The apoptosis rate of the CEP-caspase- 3 group

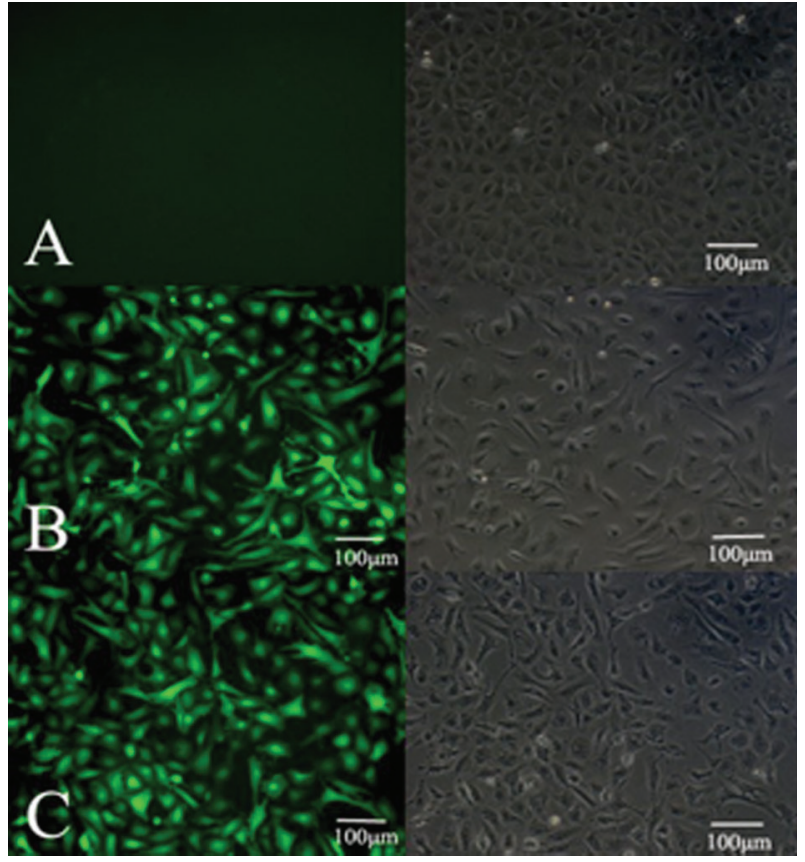

Figure 2. Evaluation of the lentivirus transduction rate, which was up to $90 \%$ as calculated by cellular enumeration using fluorescence and light microscopy $(200 \times)$. A, Control group; $B$, negative control group; $C$, caspase-3-shRNA group.

$(4.73 \pm 0.35 \%)$ was significantly decreased at $24 \mathrm{~h}$ compared with the CEP-NC and CEP-CTR groups $(13.67 \pm 0.42$ and $13.33 \pm 0.45 \%$, respectively, $P<0.05)$. Similar to the results at $24 \mathrm{~h}$, the apoptosis rate of the CEP-caspase-3 group was markedly lower than that of the CEP-NC $(9.74 \pm 0.21$ vs $23.32 \pm 0.62 \%, \mathrm{P}<0.05)$ and CEP-CTR groups $(9.74 \pm 0.21$ vs $22.41 \pm 0.69 \%, \mathrm{P}<0.05)$ at $48 \mathrm{~h}$.

\section{Discussion}

Recently, many biological therapies for disc degenerative diseases, including molecular, genetic, and cellbased strategies, have received increased attention and have been assessed for their abilities to halt and reverse disc degeneration $(24,25)$. Unlike surgical procedures, these approaches focus on the basic pathophysiological processes of disc degeneration. Molecular therapies, including the use of growth factors (26), inflammation inhibitors (27), and proteinase inhibitors (28), have exhibited limited therapeutic durations and are not suitable for treating chronic degeneration processes. Gene therapies, using virus vectors or plasmids encoding exogenous proteins to stimulate matrix synthesis or inhibit its degradation, have overcome the limitations of molecular treatment $(24,29-31)$. Cell-based therapies, including reimplantation of nucleus pulposus cells or stem cells, also have shown exciting results in animal experiments 

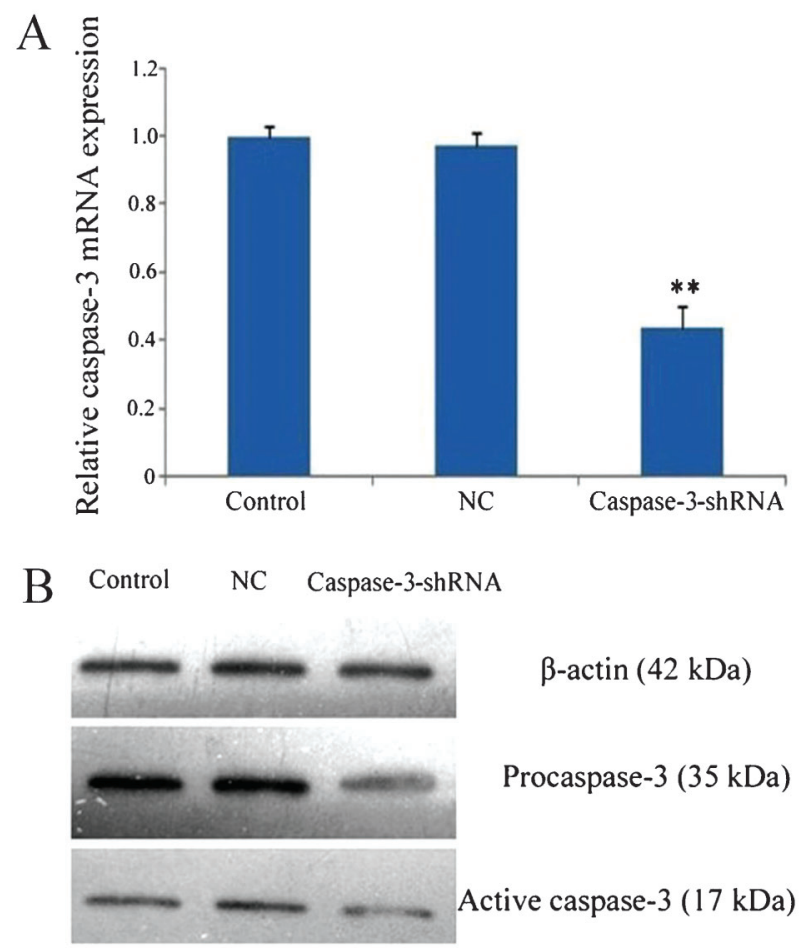

Figure 3. Expression of caspase-3 is suppressed by lentiviral caspase-3-shRNA after treatment with $1 \%$ fetal bovine serum for $48 \mathrm{~h}$, with $\beta$-actin used as an internal control. $A$, Quantitative analysis of caspase- 3 mRNA expression assessed by RT-PCR. ${ }^{* *} \mathrm{P}<0.01$ vs all other groups (one-way ANOVA). $B$, Representative Western blot showing pro- and active-caspase-3 expression determined in different groups. NC: negative control group.

$(24,30,32,33)$. However, the degeneration of the CEP, with its associated compromised diffusion of oxygen and nutrients, would likely make these approaches impractical and unable to achieve the desired results (25). Therefore, we preferred to improve the status of the CEP to increase the nutrition of the disc, which is a prerequisite for reversing or repairing disc degeneration.

Inhibition of apoptosis of disc cells can improve or reverse the degenerative process $(15,34,35)$, which provides a potential approach for improving the health of the CEP. RNAi has been widely used in gene therapy and has produced exciting results, including treatment of degenerative diseases (17). Sudo and Minami (15) applied this technique to halt disc degeneration by inhibiting apoptosis of the nucleus pulposus, as did Zhang et al. (34) in annular cells. To the best of our knowledge, this is the first investigation testing the protective effect of apoptosis inhibition on CEP cells.

Apoptosis of disc cells can be triggered by various stimuli, such as serum deprivation $(36,37), \mathrm{H}_{2} \mathrm{O}_{2}$ (38), tumor necrosis factor alpha (26), compression (39), and cyclic stretch (34), through different apoptotic cascade
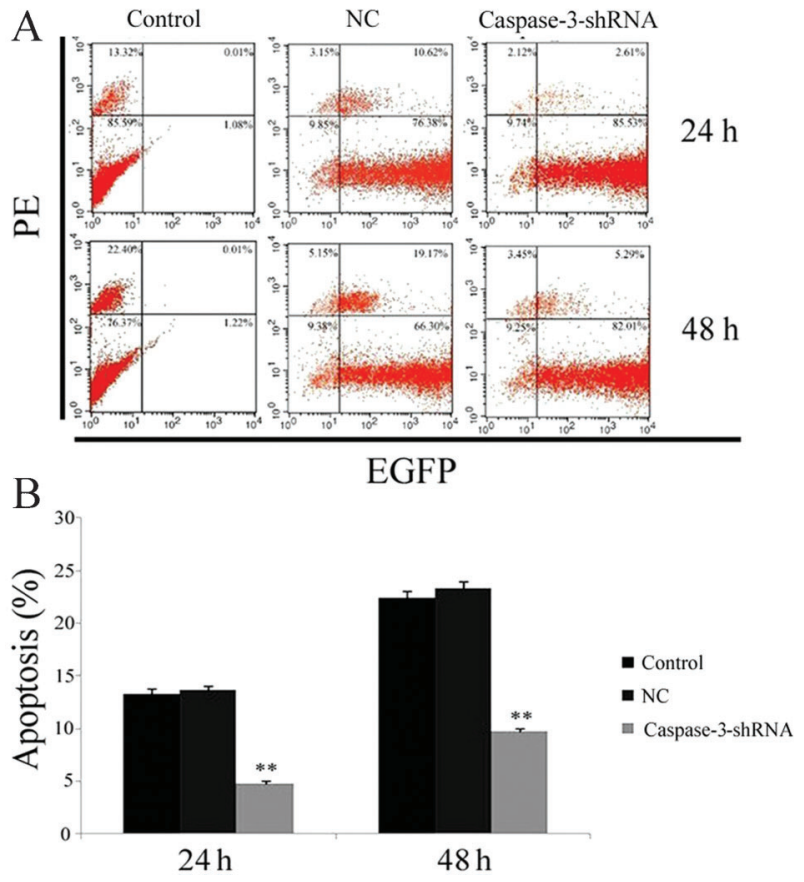

Figure 4. Evaluation of apoptosis of cartilage endplace (CEP) cells after treatment with $1 \%$ fetal bovine serum for 24 and $48 \mathrm{~h}$. $A$, Representative graphs of flow cytometry. Apoptotic cells, including early and late apoptosis, occupied the upper quadrants. $B$, Apoptosis incidence among CEP cells. Data are reported as the percentage of cell death. ${ }^{* *} \mathrm{P}<0.01 \mathrm{vs}$ all other groups (oneway ANOVA). NC: negative control group; PE: phycoerythrin; EGFP: enhanced green fluorescent protein.

pathways. Although the precise mechanism of cell apoptosis is not fully understood, caspase- 3 acts as a central executioner in the caspase apoptotic cascade pathway. Upregulation of the expression and activity of caspase-3 have been observed in different cellular apoptotic models, and specific inhibitors can successfully decrease apoptosis (36). Caspase- 3 can be a therapeutic target for regulating the processes of disc degeneration. Our findings in the CEP apoptotic model are consistent with this. Caspase- 3 activity was dramatically increased compared with that in the control cells incubated in $10 \%$ FBS, resulting in marked apoptosis as demonstrated by DAPI staining and FCM analysis. Interestingly, caspase-8 and -9 activities were also upregulated, and the precise apoptotic pathway used will require further investigation.

RNAi is highly effective in gene knockdown (19), but inefficient delivery and transient effects, its two greatest disadvantages, prohibit its application in chronic degenerative diseases. Lentivirus can easily integrate into the host genome and stably encode shRNA to overcome these drawbacks (19). As a result, lentivirus-mediated caspase-3 shRNA was explored as a means to silence endogenous caspase- 3 expression in the present study. The transduction rate was almost $90 \%$. The quantity of 
caspase- 3 mRNA was reduced by $44 \%$ compared with that observed in the CEP-NC group. Expression of proand active-caspase- 3 protein was also decreased. These data indicate that caspase- 3 can be effectively and specifically knocked down by shRNAs. Moreover, a significant decrease of the apoptotic rate in the CEPcaspase-3 group was observed in concert with suppression of the caspase- 3 expression cascade. These findings suggest that knockdown of a harmful gene during apoptosis has the potential to enable increased cell survival. However, follow-up in vivo experiments are required to determine whether the survival of the cells can delay the degeneration of the CEP and arrest or reverse the degeneration of the IVD.

\section{References}

1. Adams MA, Roughley PJ. What is intervertebral disc degeneration, and what causes it? Spine 2006; 31: 21512161, doi: 10.1097/01.brs.0000231761.73859.2c.

2. de Schepper EI, Damen J, van Meurs JB, Ginai AZ, Popham M, Hofman A, et al. The association between lumbar disc degeneration and low back pain: the influence of age, gender, and individual radiographic features. Spine 2010; 35: 531-536, doi: 10.1097/BRS.0b013e3181aa5b33.

3. Magnier $\mathrm{C}$, Boiron $\mathrm{O}$, Wendling-Mansuy $\mathrm{S}$, Chabrand $\mathrm{P}$, Deplano V. Nutrient distribution and metabolism in the intervertebral disc in the unloaded state: a parametric study. $J$ Biomech 2009; 42: 100-108, doi: 10.1016/j.jbiomech. 2008.10.034.

4. Raj PP. Intervertebral disc: anatomy-physiology-pathophysiology-treatment. Pain Pract 2008; 8: 18-44, doi: 10.1111/ j.1533-2500.2007.00171.x.

5. Roberts S, Urban JP, Evans H, Eisenstein SM. Transport properties of the human cartilage endplate in relation to its composition and calcification. Spine 1996; 21: 415-420, doi: 10.1097/00007632-199602150-00003.

6. Grunhagen T, Shirazi-Adl A, Fairbank JC, Urban JP. Intervertebral disk nutrition: a review of factors influencing concentrations of nutrients and metabolites. Orthop Clin North Am 2011; 42: 465-477, vii, doi: 10.1016/j.ocl.2011.07. 010.

7. Ariga K, Miyamoto S, Nakase T, Okuda S, Meng W, Yonenobu $\mathrm{K}$, et al. The relationship between apoptosis of endplate chondrocytes and aging and degeneration of the intervertebral disc. Spine 2001; 26: 2414-2420, doi: 10.1097/00007632-200111150-00004.

8. Grunhagen T, Wilde G, Soukane DM, Shirazi-Adl SA, Urban JP. Nutrient supply and intervertebral disc metabolism. J Bone Joint Surg Am 2006; 88 (Suppl 2): 30-35, doi: 10.2106/JBJS.E.01290.

9. Hee HT, Chuah YJ, Tan BH, Setiobudi T, Wong HK. Vascularization and morphological changes of the endplate after axial compression and distraction of the intervertebral disc. Spine 2011; 36: 505-511, doi: 10.1097/BRS.0b013e 3181d32410.

10. Rajasekaran S, Babu JN, Arun R, Armstrong BR, Shetty AP, Murugan S. ISSLS prize winner: A study of diffusion in human lumbar discs: a serial magnetic resonance imaging
Advanced cases of disc degeneration with endplate calcification or disappearance are not candidates for this approach, which is unable to regenerate the whole endplate to supply additional oxygen and nutrition. Taken together, our results lead us to conclude that lentiviral caspase-3 shRNA-mediated RNAi successfully silenced endogenous caspase- 3 expression and prevented inappropriate or premature apoptosis.

\section{Acknowledgments}

The authors thank Liang-Fei Niu for his technical assistance with lentivirus construction. The authors thank Shanghai Health Bureau (\#2009-35) for funding support.

study documenting the influence of the endplate on diffusion in normal and degenerate discs. Spine 2004; 29: 26542667, doi: 10.1097/01.brs.0000148014.15210.64.

11. Shirazi-Adl A, Taheri M, Urban JP. Analysis of cell viability in intervertebral disc: Effect of endplate permeability on cell population. J Biomech 2010; 43: 1330-1336, doi: 10.1016/ j.jbiomech.2010.01.023.

12. Scaffidi C, Fulda S, Srinivasan A, Friesen C, Li F, Tomaselli $\mathrm{KJ}$, et al. Two CD95 (APO-1/Fas) signaling pathways. EMBO J 1998; 17: 1675-1687, doi: 10.1093/emboj/17.6.1675.

13. Philchenkov A. Caspases: potential targets for regulating cell death. J Cell Mol Med 2004; 8: 432-444, doi: 10.1111/ j.1582-4934.2004.tb00468.x.

14. Ruest LB, Khalyfa A, Wang E. Development-dependent disappearance of caspase-3 in skeletal muscle is posttranscriptionally regulated. J Cell Biochem 2002; 86: 21-28, doi: $10.1002 / j \mathrm{jcb} .10211$.

15. Sudo $\mathrm{H}$, Minami A. Caspase 3 as a therapeutic target for regulation of intervertebral disc degeneration in rabbits. Arthritis Rheum 2011; 63: 1648-1657, doi: 10.1002/art.30251.

16. Hannon GJ. RNA interference. Nature 2002; 418: 244-251, doi: $10.1038 / 418244 a$.

17. Davidson BL, McCray PB Jr. Current prospects for RNA interference-based therapies. Nat Rev Genet 2011; 12: 329340, doi: 10.1038/nrg2968.

18. de Fougerolles A, Vornlocher HP, Maraganore J, Lieberman J. Interfering with disease: a progress report on siRNAbased therapeutics. Nat Rev Drug Discov 2007; 6: 443-453, doi: $10.1038 / n r d 2310$

19. Couto LB, High KA. Viral vector-mediated RNA interference. Curr Opin Pharmacol 2010; 10: 534-542, doi: 10.1016/ j.coph.2010.06.007.

20. Malashicheva AB, Kanzler B, Tolkunova EN, Trono D, Tomilin AN. [The application of lentiviral vectors for tissuespecific gene manipulations]. Tsitologiia 2008; 50: 370-375

21. Sinn PL, Sauter SL, McCray PB Jr. Gene therapy progress and prospects: development of improved lentiviral and retroviral vectors - design, biosafety, and production. Gene Ther 2005; 12: 1089-1098, doi: 10.1038/sj.gt.3302570.

22. Kakutani K, Nishida K, Uno K, Takada T, Shimomura T, Maeno K, et al. Prolonged down regulation of specific gene expression in nucleus pulposus cell mediated by RNA 
interference in vitro. J Orthop Res 2006; 24: 1271-1278, doi: 10.1002/jor.20171.

23. Suzuki T, Nishida K, Kakutani K, Maeno K, Yurube T, Takada $T$, et al. Sustained long-term RNA interference in nucleus pulposus cells in vivo mediated by unmodified small interfering RNA. Eur Spine J 2009; 18: 263-270, doi: 10.1007/s00586-008-0873-9.

24. Fassett DR, Kurd MF, Vaccaro AR. Biologic solutions for degenerative disk disease. J Spinal Disord Tech 2009; 22: 297-308, doi: 10.1097/BSD.0b013e31816d5f64.

25. Nishida K, Suzuki T, Kakutani K, Yurube T, Maeno K, Kurosaka M, et al. Gene therapy approach for disc degeneration and associated spinal disorders. Eur Spine $J$ 2008; 17 (Suppl 4): 459-466, doi: 10.1007/s00586-0080751-5.

26. Wei A, Brisby H, Chung SA, Diwan AD. Bone morphogenetic protein-7 protects human intervertebral disc cells in vitro from apoptosis. Spine J 2008; 8: 466-474, doi: 10.1016/j.spinee.2007.04.021.

27. Roberts S, Evans H, Menage J, Urban JP, Bayliss MT, Eisenstein SM, et al. TNFalpha-stimulated gene product (TSG-6) and its binding protein, lalphal, in the human intervertebral disc: new molecules for the disc. Eur Spine $J$ 2005; 14: 36-42, doi: 10.1007/s00586-004-0798-x.

28. Shimoda M, Ghobrial RM, Carmody IC, Anselmo DM, Farmer DG, Yersiz H, et al. Predictors of survival after liver transplantation for hepatocellular carcinoma associated with hepatitis C. Liver Transpl 2004; 10: 1478-1486, doi: 10.1002/lt.20303

29. Yoon ST, Park JS, Kim KS, Li J, Attallah-Wasif ES, Hutton WC, et al. ISSLS prize winner: LMP-1 upregulates intervertebral disc cell production of proteoglycans and BMPs in vitro and in vivo. Spine 2004; 29: 2603-2611, doi: 10.1097/01.brs.0000146103.94600.85.

30. Kepler CK, Anderson DG, Tannoury C, Ponnappan RK. Intervertebral disk degeneration and emerging biologic treatments. J Am Acad Orthop Surg 2011; 19: 543-553.
31. Sowa G, Westrick E, Pacek C, Coelho P, Patel D, Vadala G et al. In vitro and in vivo testing of a novel regulatory system for gene therapy for intervertebral disc degeneration. Spine 2011; 36: E623-E628, doi: 10.1097/BRS.0b013e3181 ed11c1

32. Allon AA, Aurouer N, Yoo BB, Liebenberg EC, Buser Z, Lotz JC. Structured coculture of stem cells and disc cells prevent disc degeneration in a rat model. Spine J 2010; 10: 10891097, doi: 10.1016/j.spinee.2010.09.014

33. Huang S, Tam V, Cheung KM, Long D, Lv M, Wang T, et al. Stem cell-based approaches for intervertebral disc regeneration. Curr Stem Cell Res Ther 2011; 6: 317-326, doi: 10.2174/157488811797904335.

34. Zhang YH, Zhao CQ, Jiang LS, Dai LY. Lentiviral shRNA silencing of $\mathrm{CHOP}$ inhibits apoptosis induced by cyclic stretch in rat annular cells and attenuates disc degeneration in the rats. Apoptosis 2011; 16: 594-605, doi: 10.1007/ s10495-011-0596-y.

35. Ding F, Shao ZW, Xiong LM. Cell death in intervertebral disc degeneration. Apoptosis 2013; 18: 777-785, doi: 10.1007/ s10495-013-0839-1.

36. Park JB, Park IC, Park SJ, Jin HO, Lee JK, Riew KD. Antiapoptotic effects of caspase inhibitors on rat intervertebral disc cells. J Bone Joint Surg Am 2006; 88: 771-779, doi: 10.2106/JBJS.E.00762.

37. Liu J, Wang J, Zhou Y. Upregulation of BNIP3 and translocation to mitochondria in nutrition deprivation induced apoptosis in nucleus pulposus cells. Joint Bone Spine 2012; 79: 186-191, doi: 10.1016/j.jbspin.2011.04.011.

38. Kim KW, Ha KY, Lee JS, Rhyu KW, An HS, Woo YK. The apoptotic effects of oxidative stress and antiapoptotic effects of caspase inhibitors on rat notochordal cells. Spine 2007; 32: 2443-2448, doi: 10.1097/BRS.0b013e318157395a.

39. Walter BA, Korecki CL, Purmessur D, Roughley PJ, Michalek AJ, latridis JC. Complex loading affects intervertebral disc mechanics and biology. Osteoarthritis Cartilage 2011; 19 : 1011-1018, doi: 10.1016/j.joca.2011.04.005. 